\title{
Aerodynamic admittance influence on buffeting performance of suspension bridge with streamlined deck
}

\author{
Yao Gang1, Yang Yang ${ }^{2}, \mathrm{Wu} \mathrm{Bo}^{3}$, Liu Lianjie ${ }^{4}$, Zhang Liangliang \\ $1,2,3,5$ Key Laboratory of New Technology for Construction of Cities in Mountain Area, Ministry of \\ Education, Chongqing, China \\ 1,2,3,4, School of Civil Engineering, Chongqing University, Chongqing, China \\ ${ }^{4}$ Department of Highway Engineering, Chongqing Construction Science Research Institute, Chongqing, \\ China \\ ${ }^{2}$ Corresponding author \\ E-mail: ${ }^{1}$ yaocqu@vip.sina.com, ${ }^{2} y y 20052710 @ 163 . c o m,{ }^{3}$ wuswjtu@yeah.net, ${ }^{4} 20121601012 @$ cqu.edu.cn, \\ 5zll200510@126.com
}

Received 28 January 2018; received in revised form 24 June 2018; accepted 5 August 2018 DOI https://doi.org/10.21595/jve.2018.19681

Check for updates

Copyright (C) 2019 Yao Gang, et al. This is an open access article distributed under the Creative Commons Attribution License, which permits unrestricted use, distribution, and reproduction in any medium, provided the original work is properly cited.

\begin{abstract}
Buffeting performance is growing sensitive to external and internal factors with increasing span of bridge. Aerodynamic admittance is an essential parameter in analyzing buffeting performance. In this paper, aerodynamic admittance in different conditions were conducted in wind tunnel tests by section model. Three kinds of aerodynamic admittance functions were used to calculating buffeting performance respectively. It is found that the aerodynamic admittance of streamlined deck is closely related to wind attack angle, and has a small difference at different wind speeds. However, the influence of aerodynamic admittance on buffeting performance is affected by the wind speed significantly. Under given conditions, adopting the Sears function as the admittance function of a similar streamlined box girder is reasonable, while the buffeting performance result obtained by adopting an admittance function as 1.0 is very conservative.
\end{abstract}

Keywords: aerodynamic admittance, buffeting performance, wind tunnel test, long-span bridge.

\section{Introduction}

Buffeting performance is a forced vibration caused by turbulence wind. This vibration can interfere many features of bridge, such as fatigue damage, discomfort for vehicles and pedestrians. Buffeting performance is growing sensitive to external and internal factors with increasing span. Researchers have been working in external factors influence on buffeting performance, including topography [1], extreme value of typhoon [2], turbulence characteristics [3], turbulent spatial correlation coefficient [4], skew wind [5-7], design and measured power spectrum [8], non-stationary and stochastic excitation [2, 9-11]. There are also a multitude of researchers working in internal factors simultaneously, including multiple tuned mass dampers [12-15], mechanically driven flaps [16-18], mid-tower [19], catwalk [20], central buckle [21], and slotted deck [22]. Study method makes varied with a tendency more proper to reality, with improved analysis theories in buffeting performance, such as linear regression [6], non-linear regression analysis [21], evolutionary power spectral density [19,23], varying frequency-increment sweeping method [10], and three-dimensional simulation [24, 25]. Researches above demonstrate that the buffeting performance is becoming an extremely refined analysis. Aerodynamic admittance is of great importance in the evaluation of the buffeting and response of structures. Buffeting performance with considering of aerodynamic admittance can reflect the vibration of bridge more closely to reality and meet the requirement of refined analyses. However, a handful of research is concentrated in aerodynamic admittance effect. Wang H. [7] compared two types of aerodynamic admittance function, 1.0 and Sear functions, in calculating the buffeting performance. Tubino F. [26] introduced a generalized quasi-static theory, defining new relationships among the flutter derivatives and the aerodynamic admittance functions. Costa C. [27] numerically evaluated 
aerodynamic admittance functions for rectangular sections and compared with experimental and analytical results. Massaro M. [28] investigated the effect of aspect-ratio on the aerodynamic admittance of thin aero foils, flat plates and thin bridge section. Hejlesen M. M. [29] estimated the aerodynamic admittance of bridge sections by mesh-free vortex method and confirmed its feasibility by comparing to available wind tunnel data. Zhao L. [30] proposed a new identification algorithm about the admittance function and validated it by a comparison between the numerical calculation and wind tunnel tests. Hua X. G. [31] developed an improved perturbation method for the statistical identification of structural parameters by using the measured modal parameters with randomness.

The buffeting performance is of great importance during the service period of long-span bridges, aerodynamic and dynamic characteristics could directly contribute to the buffeting performance. For the aerodynamic characteristics, the most important factor may be the aerodynamic admittance as it reflects the unsteady features in buffeting forces. Influence of aerodynamic admittance on buffeting performance is still inadequate. Researches above paid particular emphasis on exploring typical aerodynamic admittance function, such as Sear function, Davenport function. There is rarely research about influence of measured aerodynamic admittance on buffeting performance. The buffeting performance considering measured aerodynamic admittance are closer to practical situation.

In this study, aerodynamic admittance in different conditions were conducted in wind tunnel tests by section model. Aerodynamic admittance functions were deduced. Three type aerodynamic admittance functions were used to calculate buffeting performance respectively in time domain, which accounted for structural nonlinearities. Taking the Cuntan Yangtze bridge as an example, the differences of buffeting performance with three kinds of aerodynamic admittance functions were analyzed in time domain via a suspension bridge model built on ANSYS platform. Effects of aerodynamic admittance on buffeting performance of bridge were summarized. The analytical results are expected to provide references for the buffeting performance analysis, fatigue damage and comfort of wind-vehicle-bridge system analysis.

\section{Description of wind tunnel test}

Cuntan Yangtze bridge is taken as the project background. The main girder is a streamlined closed, flat box girder. Width of the deck section is $42.0 \mathrm{~m}$ and thickness of the section is $3.5 \mathrm{~m}$. Attachment structures have a strong influence on aerodynamic characters. Therefore, guardrails and lead rails are considered in wind tunnel test. Bridge section model includes pedestrian guardrail, anti-collision guardrail, center separation band guardrail and lead rail, and the detail dimensions are shown in Fig. 1.

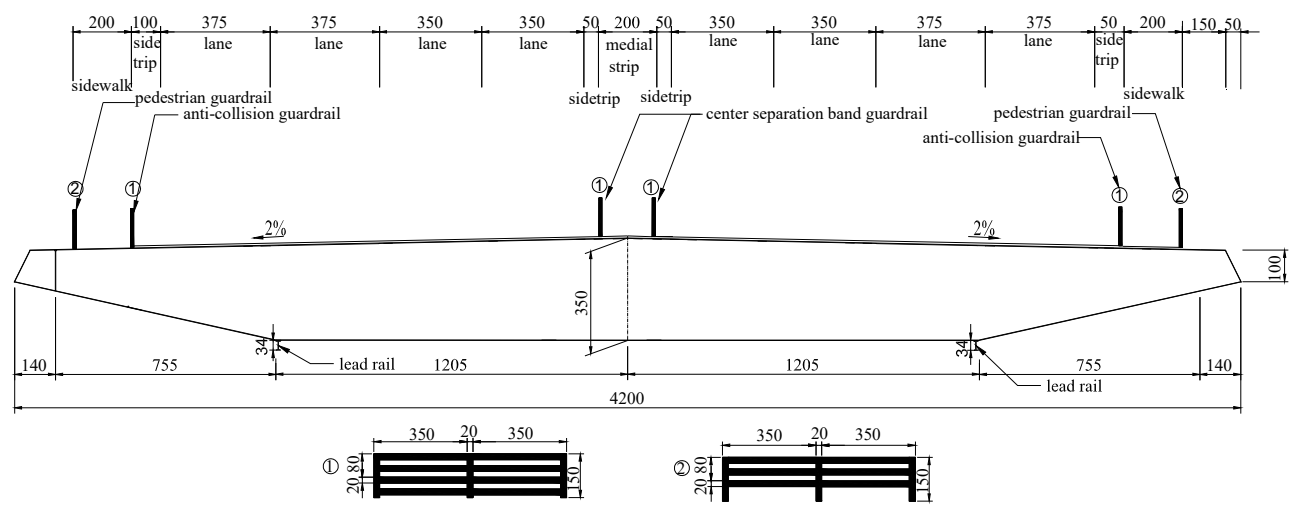

Fig. 1. Dimensions of standard cross section $(\mathrm{cm})$

In order to get the static force coefficients and aerodynamic admittances of real bridge, two 
bridge section models were used in wind tunnel test. Aerostatic coefficients were tested by subsection elastic model in first test section of wind tunnel, which were used to calculate aerostatic load in buffeting performance. Aerodynamic admittances were measured by subsection rigid model in the second test section of wind tunnel.

\subsection{Description of subsection elastic model}

Subsection elastic model was made of wood. Pedestrian guardrails, anti-collision guardrails and center separation band guardrails were manufactured in plastic plates by machine. The subsection elastic model had a scalar of 1/60 to the real bridge section, and it was shown in Fig. 2 . Wind tunnel test requires that the subsection elastic model is similar to the real bridge in geometric dimensions, as well as frequency and damping ratio. But actually, the subsection elastic model is not exactly the same with real bridge in all aspects. Deviation is allowable in the wind tunnel test. Allowable damping ratio deviation should be controlled less than $10 \%$ and allowable deviation of frequency, mass should be controlled less than $3.0 \%$. From Table 1, it can be calculated that the deviation is $4.3 \%$ on vertical bending damping ratio and $3.8 \%$ on torsion damping ratio, and other parameters kept the same as prototype model. As a consequence, subsection elastic model can meet the demand of experiment.

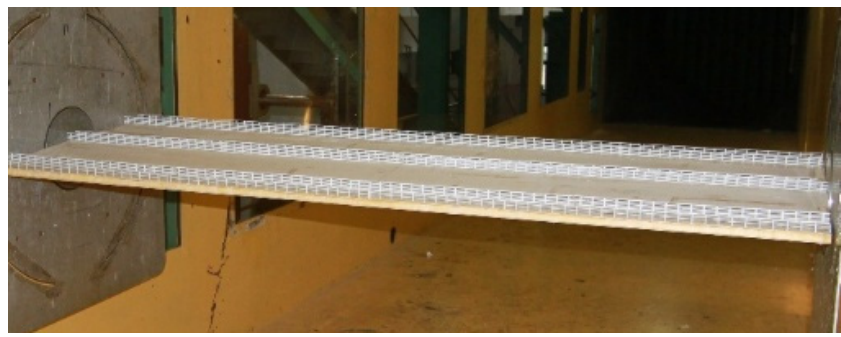

Fig. 2. Subsection elastic model

Table 1. Design parameters of section elastic model

\begin{tabular}{|c|c|c|c|c|}
\hline Parameter & Unit & Actual value & Required value & Value in test \\
\hline Height & $\mathrm{m}$ & 3.5 & 0.0583 & 0.0583 \\
\hline Width & $\mathrm{m}$ & 42.0 & 0.7 & 0.7 \\
\hline Linear mass & $\mathrm{kg} / \mathrm{m}$ & 27600 & 7.667 & 7.667 \\
\hline Linear mass moment of inertia & $\mathrm{kg} \cdot \mathrm{m}^{2} / \mathrm{m}$ & 5137700 & 0.3987 & 0.3987 \\
\hline Vertical bending frequency & $\mathrm{Hz}$ & 0.174 & 2.216 & 2.216 \\
\hline Vertical bending damping ratio & $\%$ & 0.5 & 0.389 & 0.372 \\
\hline Torsion frequency & $\mathrm{Hz}$ & 0.39726 & 5.404 & 5.404 \\
\hline Torsion damping ratio & $\%$ & 0.5 & 0.439 & 0.422 \\
\hline
\end{tabular}

\subsection{Description of subsection rigid model}

The subsection rigid model was made up of measured section and compensation section was shown in Fig. 3. The subsection rigid model had a ratio of $1 / 300$ with the real bridge section. The model was made from light and thin-walled wood material and possessed enough stiffness avoiding deformation and vibration in the test. A square steel frame was fixed in wind tunnel floor and an aluminum bar in the middle of the frame beam was vertically mounted to fix the compensation section. Compensation section was installed in the aluminum bar and had a space less than $2.0 \mathrm{~mm}$ with the measuring section. The importance of three-dimensional effects was aspect-ratio dependent (neglecting any end effect). The results obtained on a rigid span were confirmed when considering a flexible span. The subsection rigid model was tested after installation, and the basic frequency of wide-body flat steel box girder in-plane was $56.0 \mathrm{~Hz}$, out-of-plane basic frequency was $35.0 \mathrm{~Hz}$, reverse fundamental frequency was $81.0 \mathrm{~Hz}$. All 
frequency was much larger than the measurement band of buffeting aerodynamics. Consequently, the system can meet the requirements of a high frequency force measuring test. The sampling frequency adopted for aerodynamic force was $100.0 \mathrm{~Hz}$.

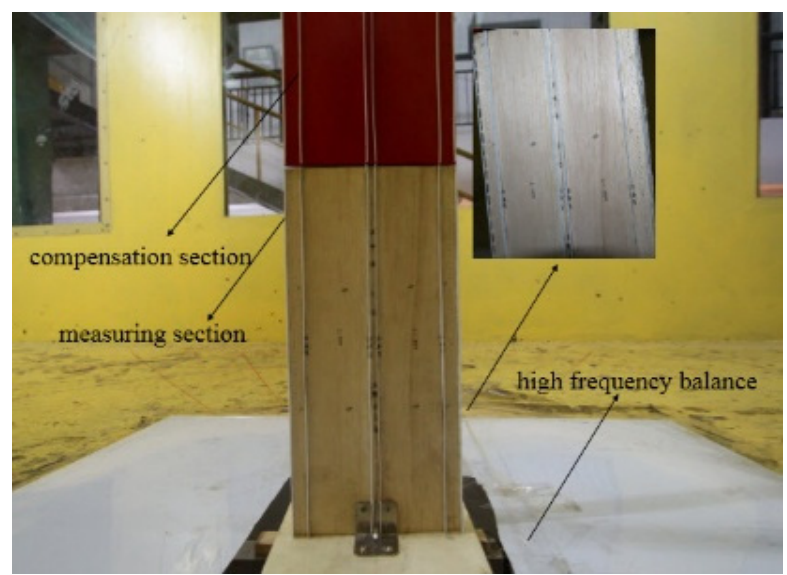

Fig. 3. Subsection rigid model

\subsection{Description of wind tunnel}

The tests were performed in XNJD-1 wind tunnel, and the geometry of wind tunnel was shown in Fig. 4. Static force coefficients were measured in the first test section and aerodynamic admittances were measured in the second test section of wind tunnel. The maximum wind velocity was $45.0 \mathrm{~m} / \mathrm{s}$ and the minimum wind velocity was $0.5 \mathrm{~m} / \mathrm{s}$. Both turbulence flow less than $0.1 \%$ and uniform flow can be generated by this wind tunnel. Lattice-grid was used to producing turbulence flow and position of lattice-grid was shown in Fig. 4. The section model was placed in the middle of the test section and it spanned all the test section width. The effect of the boundary layer was neglected.

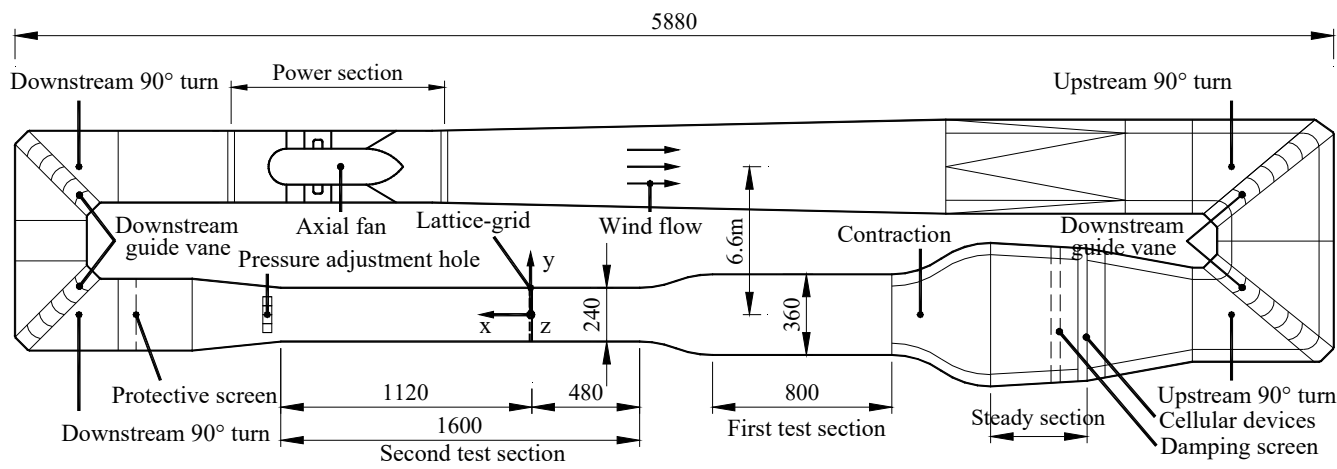

Fig. 4. Geometry of wind tunnel $(\mathrm{cm})$

Two kinds of the wind speed acquisition sensors were used. One was the hot-wire anemometry sensor shown in Fig. 5 and the other was turbulent flow instrumentation (TFI) series 100 Cobra Probe sensor shown in Fig. 6. The former was placed in the upstream with $0.4 \mathrm{~m}$ from the side wall and $0.2 \mathrm{~m}$ from the lattice-grid at the height of $0.9 \mathrm{~m}$. It was used to measure the mean wind speed, with an immediately display screen outside of the wind tunnel through a small hole of the side wall, in order to show the upstream speed instantaneously. The latter was a pressure probe placed in the selected downstream monitor points behind the lattice-grid, which can provide dynamic, three-component velocities and local static pressure measurements simultaneously. The 
mean wind speed in the same position measured by the two kinds of sensors had been verified before the experiment.

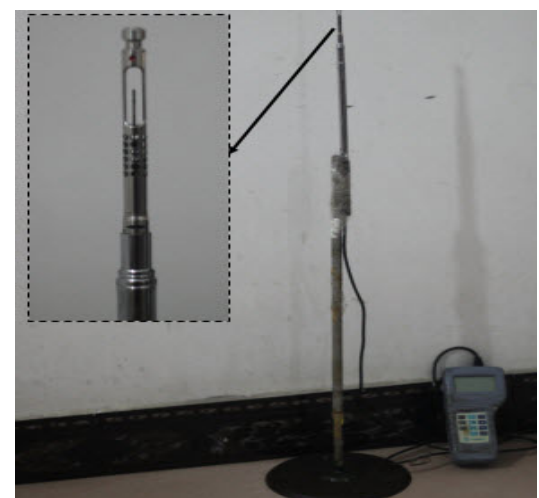

Fig. 5. Hot-wire anemometry sensor

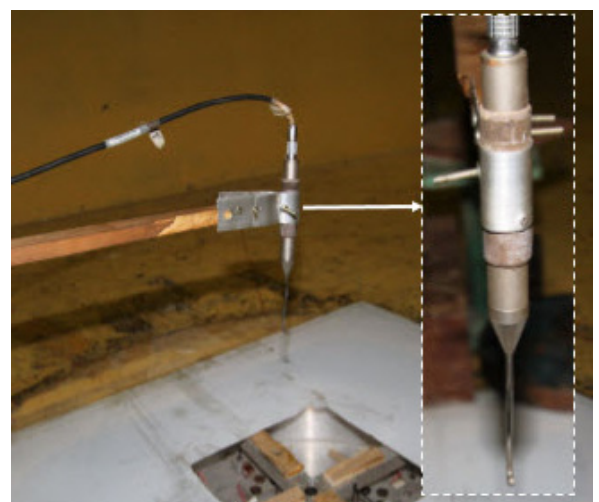

Fig. 6. TFI cobra probe

Passive lattice-grid technology is a kind of commonly used method to generate turbulent flow. Lattice-grid was adopted in the test, and the detail information was shown in Fig. 7. Both turbulence intensity and turbulence integral scale were calculated from data measured by the TFI Cobra Probe.

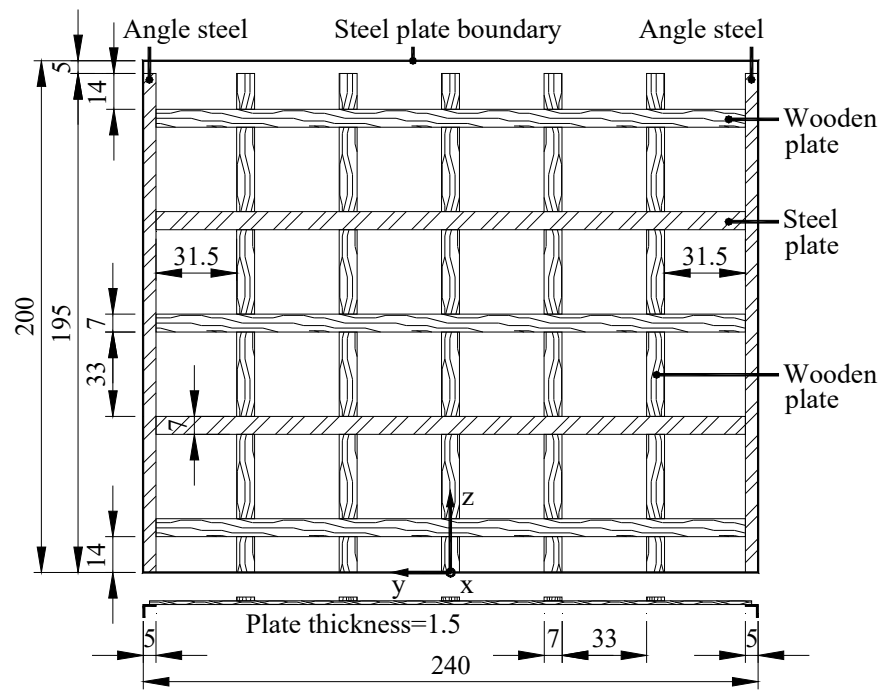

Fig. 7. Geometry of lattice-grid (cm)

\subsection{Results of aerostatic coefficients}

Aerostatic coefficients and its derivatives were used to calculate the buffeting loads, and they were obtained by static test in first test section of wind tunnel. Tests were done in uniform flow. Subsection elastic model was used in testing the aerostatic coefficients. Mechanical model of static force at wind axis and body axis can be shown in Fig. 8. $F_{H}$ is the lateral drag force in the conventional axis, $F_{V}$ is the vertical lift force in the conventional axis, $M$ is the moment in the conventional axis. $F_{D}$ is the lateral drag force in the wind axis, $F_{L}$ is the vertical lift force in the wind axis, $M_{Z}$ is the moment in the wind axis. $\alpha$ is the wind attack angle. $F_{H}, F_{V}$ and $M$ could be obtained directly by subsection elastic model in wind tunnel test. 


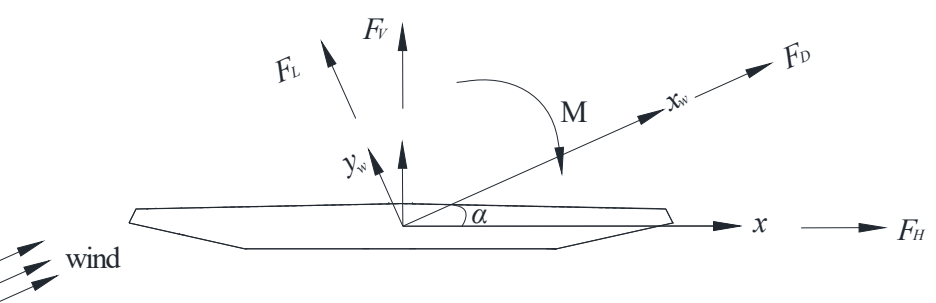

Fig. 8. Mechanical model of static force at wind axis and conventional axis

Forces and moments can be transformed in wind axis and conventional axis, and the relationship can be expressed in Eq. (1), Eq. (2) and Eq. (3):

$F_{L}=-F_{H} \sin \alpha+F_{V} \cos \alpha$,

$F_{D}=F_{H} \cos \alpha+F_{V} \sin \alpha$,

$M_{Z}=M$.

Aerostatic coefficients could be obtained by Eq. (4), Eq. (5) and Eq. (6):

$$
\begin{aligned}
C_{L}(\alpha) & =\frac{F_{L}}{0.5 \rho U^{2} B L}, \\
C_{D}(\alpha) & =\frac{F_{D}}{0.5 \rho U^{2} B L}, \\
C_{M}(\alpha) & =\frac{F_{M}}{0.5 \rho U^{2} B^{2} L},
\end{aligned}
$$

where $U$ represents mean wind velocity, $\rho$ represents density of air, $B$ represents width of the bridge deck, $C_{L}, C_{D}$ and $C_{M}$ represent dimensionless lift, drag and moment coefficients, $C_{L}^{\prime}, C_{D}^{\prime}$ and $C_{M}^{\prime}$ represent derivatives of lift, drag and moment coefficients respectively. Results of aerostatic coefficients and its derivatives were shown in Fig. 9 , and results at $0^{\circ}$ wind attack angle were used in analyzing the buffeting performance of long-span bridge.

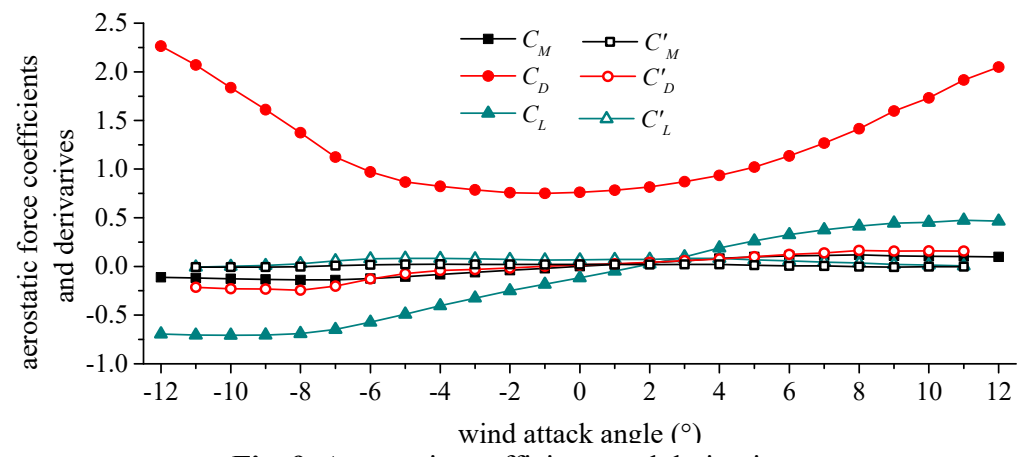

Fig. 9. Aerostatic coefficients and derivatives

\subsection{Results of aerodynamic admittance}

Subsection rigid model was used to obtain the aerodynamic admittance in turbulent flow. The five component high frequency balance was fixed on the wind tunnel floor surface. Three component of power spectrum of turbulent wind can be respectively gotten by FFT (fast Fourier transform) with MatLab. Sensor location of TFI Cobra Probe was $2.4 \mathrm{~m}$ from the air grid in the horizontal direction and $0.3 \mathrm{~m}$ from the bottom of the wind tunnel in the vertical direction. The arrangement of aerodynamic admittance test was shown in Fig. 10. Five working conditions 
considered in the wind tunnel test were shown in Table 2. Comparison of results of equivalent admittance function from five repeated experiments were exhibited in Fig. 11 and fitting results of aerodynamic admittance were exhibited in Fig. 12. In the Fig. 11 and Fig. 12, the equivalent drag, lift and moment admittance were the square of the absolute value of drag, lift and moment admittance respectively, and they were the dimensionless parameters. The reduced frequency was a dimensionless parameter relating to frequency, width of bridge and wind speed.

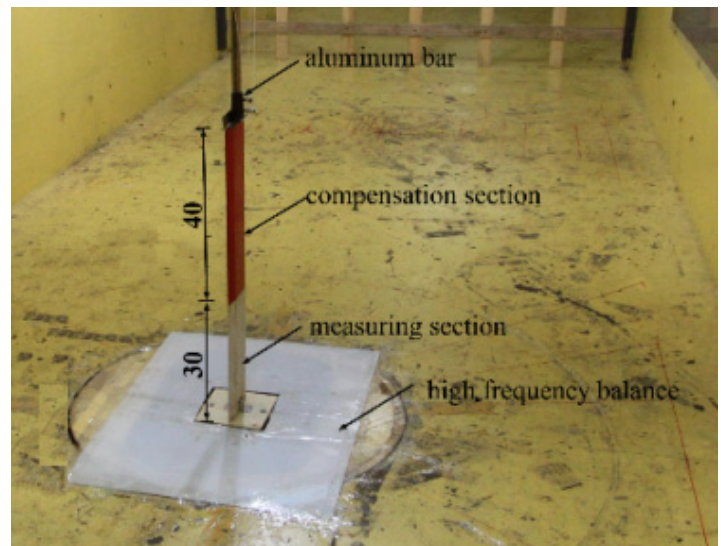

Fig. 10. Arrangement of aerodynamic admittance test $(\mathrm{cm})$

Table 2. Working conditions considered in the wind tunnel test

\begin{tabular}{|c|c|c|c|c|c|}
\hline Working condition & W8-W0 & W10-W0 & W12-W0 & W12+W3 & W12-W3 \\
\hline Wind speed $(\mathrm{m} / \mathrm{s})$ & 8.47 & 10.15 & 12.58 & 12.58 & 12.58 \\
\hline Wind attack angle $\left(^{\circ}\right)$ & 0 & 0 & 0 & +3 & -3 \\
\hline
\end{tabular}

Comparing W8-W0, W10-W0 and W12-W0 working conditions in Fig. 11 and Fig. 12, the identification results of aerodynamic admittance had a small difference at different wind speeds. Comparing W12-W0, W12+W3 and W12-W3 working conditions in Fig. 11 and Fig. 12, the results of the equivalent admittance function had an obvious difference under different wind attack angles. No distinct relationship of admittance function following wind attack angle was found under the condition of passive incoming flow. Lift admittance was the largest in the aerodynamic admittance. Draft admittance increased obviously with the increasing of wind attack angle, and the trend of change was evident. Lift and moment admittance decreased with the increasing of wind attack angle, and the trend of change was slighter than draft admittance.

Equivalent aerodynamic admittance method was built on the improvement cross-power spectrum method [32]. Buffeting force spectrum was measured from the placed scale model with high frequency dynamic balance after the initial value checked. Turbulent wind power spectrum was measured by the TFI Cobra Probe placed in the same environment. In order to get a more accurate bridge buffeting response, aerodynamic admittance expression of wide-body flat steel box girder was presented in this paper by custom equation in MatLab with Eq. (7):

$\left|\chi_{R}(k)\right|^{2}=\frac{\gamma}{1+\beta k^{\delta}}$

where $\chi_{D u}, \chi_{L u}$ and $\chi_{M u}$ represent draft, lift and moment admittance. Where $\gamma, \beta$ and $\alpha$ represent fitting parameters. The condition with $0^{\circ}$ wind attack angle was the most widely used condition in many research $[1-4,8-12]$. Therefore, conditions with $0^{\circ}$ wind attack angle were chosen to fit the aerodynamic admittance expression in three directions. The fitting data of aerodynamic admittance was shown in Table 3. 
AERODYNAMIC ADMITTANCE INFLUENCE ON BUFFETING PERFORMANCE OF SUSPENSION BRIDGE WITH STREAMLINED DECK. YAO GANG, YANG YANG, WU BO, LIU LIANJIE, ZHANG LIANGLIANG

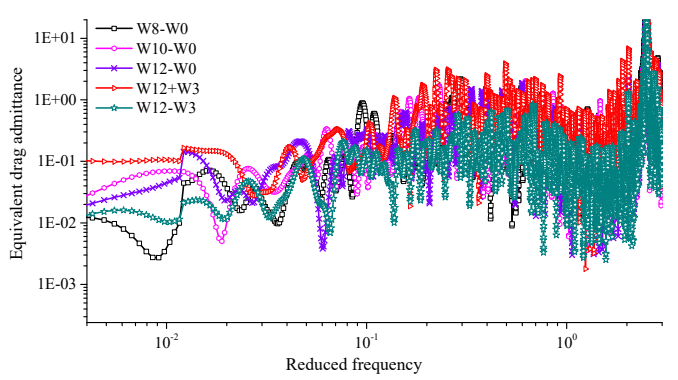

a) Equivalent drag admittance

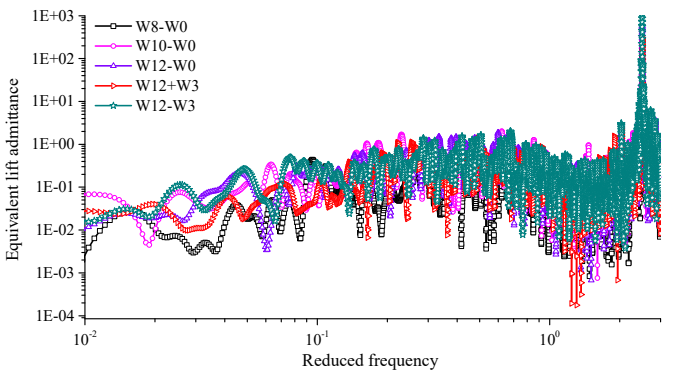

b) Equivalent lift admittance

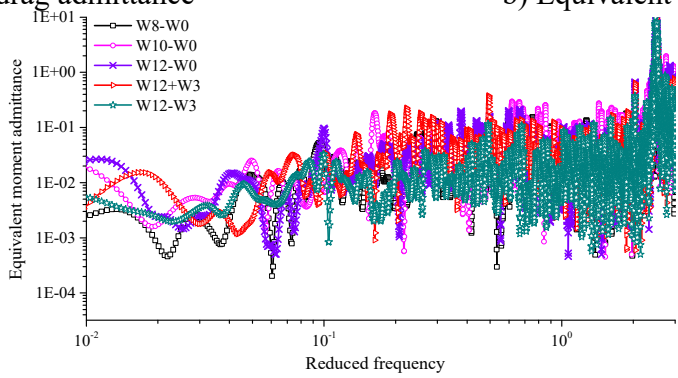

c) Equivalent moment admittance

Fig. 11. Identification results of aerodynamic admittance

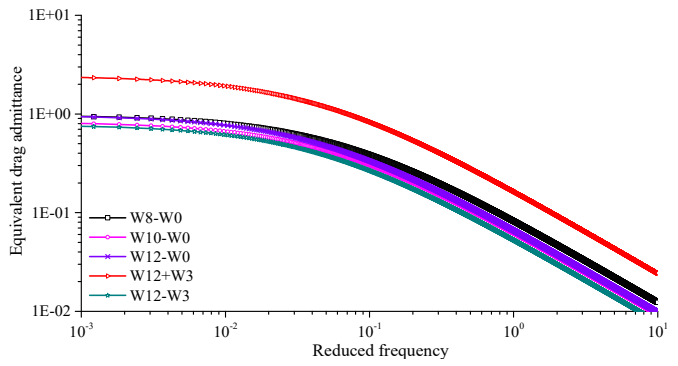

a) Equivalent drag admittance

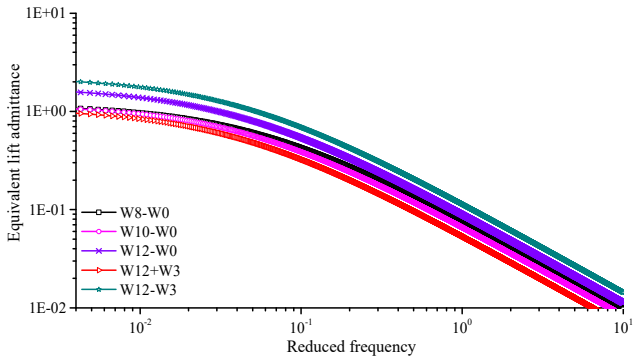

b) Equivalent lift admittance

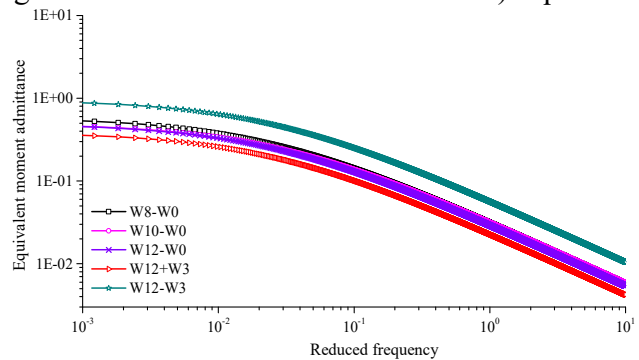

c) Equivalent moment admittance

Fig. 12. Fitting results of aerodynamic admittance

Table 3. The fitting data of aerodynamic admittance

\begin{tabular}{|c|c|c|c|}
\hline$X_{R}$ & $\gamma$ & $\beta$ & $\sigma$ \\
\hline$\chi_{D u}$ & 1.18 & 12.26 & 0.92 \\
\hline$\chi_{L u}$ & 0.62 & 14.13 & 0.75 \\
\hline$\chi_{M u}$ & 0.96 & 8.25 & 0.82 \\
\hline
\end{tabular}

\section{Sectional forces in time domain}

The wind load acting on bridge deck can be divided into two parts, including self-excited 
aerodynamic loads and turbulent loads. Buffeting loads can be expressed in Eq. (8), Eq. (9) and Eq. (10) [24]:

$L(t)=L_{s e}(t)+L_{b}(t)$,
$D(t)=D_{s e}(t)+D_{b}(t)$,
$M(t)=M_{s e}(t)+M_{b}(t)$,

where $L_{s e}, D_{s e}$ and $M_{s e}$ represent lift, drag and moment due to self-excited motions, respectively. Self-excited, and buffeting forces are shown schematically in Fig. 13.

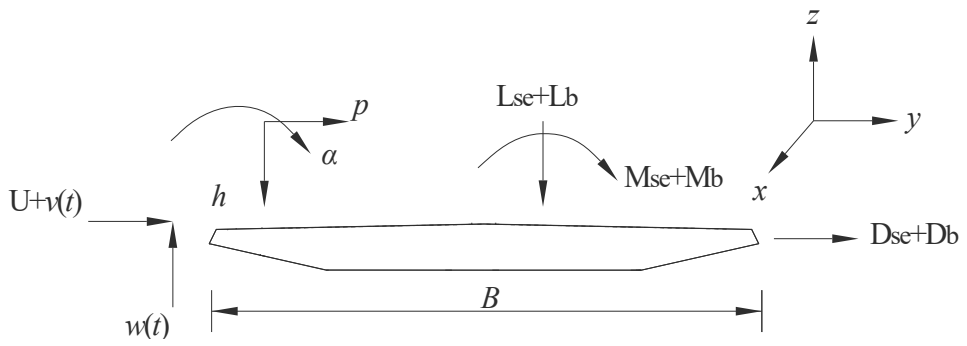

Fig. 13. Aerodynamic forces on bridge deck

The lift, drag and moment of the self-excited part of the force at per unit length of the deck can be expressed in Eq. (11), Eq. (12) and Eq. (13):

$$
\begin{aligned}
& L_{s e}(t)=\frac{1}{2} \rho U^{2}(2 B)\left[K H_{1}^{*} \frac{\dot{h}}{U}+K H_{2}^{*} \frac{B \dot{\alpha}}{U}+K^{2} H_{3}^{*} \alpha+K^{2} H_{4}^{*} \frac{h}{B}+K H_{5}^{*} \frac{\dot{p}}{U}+K^{2} H_{6}^{*} \frac{p}{B}\right], \\
& D_{s e}(t)=\frac{1}{2} \rho U^{2}(2 B)\left[K P_{1}^{*} \frac{\dot{p}}{U}+K P_{2}^{*} \frac{B \dot{\alpha}}{U}+K^{2} P_{3}^{*} \alpha+K^{2} P_{4}^{*} \frac{p}{B}+K P_{5}^{*} \frac{\dot{h}}{U}+K^{2} P_{6}^{*} \frac{h}{B}\right], \\
& M_{s e}(t)=\frac{1}{2} \rho U^{2}\left(2 B^{2}\right)\left[K A_{1}^{*} \frac{\dot{h}}{U}+K A_{2}^{*} \frac{B \dot{\alpha}}{U}+K^{2} A_{3}^{*} \alpha+K^{2} A_{4}^{*} \frac{p}{B}+K A_{5}^{*} \frac{\dot{p}}{U}+K^{2} A_{6}^{*} \frac{p}{U}\right],
\end{aligned}
$$

where $\rho$ represents density of air; $B$ represents width of the bridge deck; $K$ represents reduced frequency, and $K=B \omega / U, \omega$ represents circular frequency of the bridge motion; $H i^{*}, P i^{*}, A i^{*}$ $(i=1,2,3,4,5,6)$ represent flutter derivatives of the bridge deck measured through the wind tunnel tests shown in Fig. 4. The identified flutter derivatives were input as the coefficients in the aeroelastic stiffness and damping matrices of Matrix27; $h, p$ and $\alpha$ represent vertical, horizontal and rotational displacement of the bridge deck, respectively. Buffeting loads at per unit span length are expressed in Eq. (14), Eq. (15) and Eq. (16):

$$
\begin{aligned}
& \left.L_{b}(t)=\frac{1}{2} \rho U^{2} q B\left[2 C_{L}(\theta) \chi_{L u} \frac{u(t)}{U}+\left(C_{L}^{\prime}(\theta)\right)+C_{D}(\theta)\right) \chi_{L u} \frac{w(t)}{U}\right] \\
& \left.D_{b}(t)=\frac{1}{2} \rho U^{2} B\left[2 C_{L}(\theta) \chi_{L u} \frac{u(t)}{U}+C_{D}^{\prime}(\theta)\right) \chi_{D w} \frac{w(t)}{U}\right] \\
& \left.M_{b}(t)=\frac{1}{2} \rho U^{2} B^{2}\left[2 C_{M}(\theta) \chi_{L u} \frac{u(t)}{U}+C_{M}^{\prime}(\theta)\right) \chi_{M w} \frac{w(t)}{U}\right]
\end{aligned}
$$

where $L_{b}, D_{b}$ and $M_{b}$ represent lift, drag and moment due to buffeting effects, respectively. $C_{L}(\theta)$, $C_{D}(\theta)$ and $C_{M}(\theta)$ are dimensionless aerostatic coefficients (lift, drag and moment coefficients) at a specified wind angle. $C_{L}^{\prime}(\theta), C_{D}^{\prime}(\theta)$ and $C_{M}^{\prime}(\theta)$ are its derivatives. In this buffeting performance analysis, the $\theta$ is defined as $0^{\circ}$, and the aerostatic coefficients and its derivatives are defined 
according to Fig. 8. $u(t)$ and $w(t)$ are wind velocity fluctuations in the horizontal and vertical directions, respectively. $\chi_{L u}, \chi_{D u}$ and $\chi_{M u}$ are aerodynamic admittance.

\section{Bridge model on Ansys platform}

Cuntan Yangtze bridge including main section and approach bridge is located in Chongqing, China. The middle span is a suspension structure with $880.0 \mathrm{~m}$. Ratio of rise to span in this bridge is $1 / 8.8$ and the distance of two main cables is $39.2 \mathrm{~m}$. The bridge elevation and the input point of turbulence wind are shown in Fig.14, and fluctuating wind simulation points are numbered. Height of fluctuating wind simulation points on main cable are given in Table 4. The north tower is $194.5 \mathrm{~m}$ and the south tower is $199.5 \mathrm{~m}$ in height. The main cable is made up of 127 high strength galvanized steel wires.

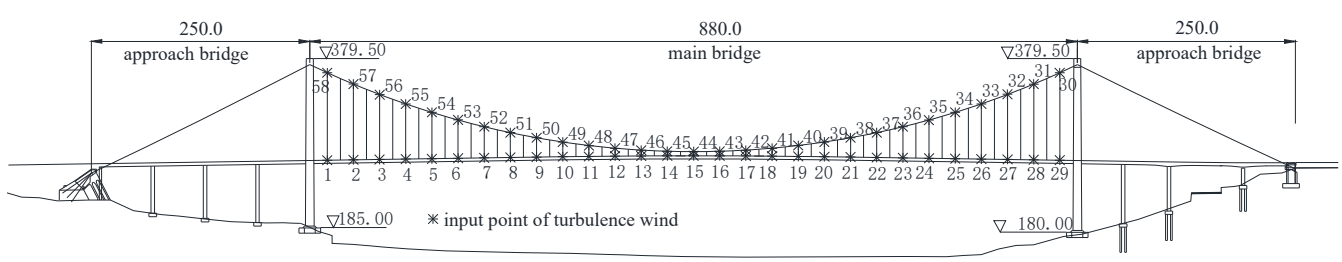

Fig. 14. Cuntan Yangtze bridge's configuration

Table 4. Height of fluctuating wind simulation point on main cable

\begin{tabular}{|c|c|c|c|c|c|c|c|c|}
\hline Number & $(58,30)$ & $(57,31)$ & $(56,32)$ & $(55,33)$ & $(54,34)$ & $(53,35)$ & $(52,36)$ & 51 \\
\hline Height $(\mathrm{m})$ & 213.06 & 206.01 & 199.14 & 192.18 & 185.28 & 178.38 & 171.48 & 164.58 \\
\hline Number & $(50,38)$ & $(49,39)$ & $(48,40)$ & $(47,41)$ & $(46,42)$ & $(45,43)$ & 44 & 37 \\
\hline Height $(\mathrm{m})$ & 161.36 & 158.1 & 154.77 & 151.46 & 148.16 & 144.86 & 141.58 & 164.58 \\
\hline
\end{tabular}

A three-dimensional finite element model was set up on the ANSYS platform. Spatial beam4 element was used to simulate main girder and beam44 element was used to simulate main towers. Link10 element with three degrees of freedom was used to simulate main cables and suspenders. Pavement and railings' stiffness contributions were neglected and lumped masses account for them were equal distributed to the main girder with mass 21 element. Combin 14 element was selected to simulate damper. According to the design, material properties and elements' characteristic were added in the model and given in Table 5. Ernst equation of equivalent modulus of elasticity were used to calculate linearized stiffness of back cables' nonlinearity stiffness. According to the bridge design, the deck and main towers were coupled in three degrees of freedom, including vertical displacement, transverse displacement, and rotation around longitudinal direction. Two main cables were fixed on the top of towers, and the bottoms of main cables were fixed at the bases. Two main towers were also fixed at the bases without considering the soil-pile structure interaction. The bridge was dispersed into 818 elements and 721 nodes.

Table 5. Type of material

\begin{tabular}{|c|c|c|c|c|c|}
\hline Number & $\begin{array}{c}\text { Modulus of } \\
\text { elasticity }(\mathrm{Pa})\end{array}$ & $\begin{array}{c}\text { Poisson's } \\
\text { ratio }\end{array}$ & $\begin{array}{c}\text { Density } \\
\left(\mathrm{N} / \mathrm{m}^{3}\right)\end{array}$ & Material & Application \\
\hline 1 & $2.10 \mathrm{E}+11$ & 0.3 & 7850 & Q345QD & Main girder \\
\hline 2 & $2.00 \mathrm{E}+11$ & 0.3 & 8650 & $\begin{array}{c}\text { High-strength } \\
\text { steel wire }\end{array}$ & $\begin{array}{c}\text { Main cable, suspension } \\
\text { cable }\end{array}$ \\
\hline 3 & $3.45 \mathrm{E}+10$ & 0.2 & 2650 & C50 RC & Main tower \\
\hline 4 & $1.00 \mathrm{E}+15$ & 0 & 0 & - & Rigid transverse beam \\
\hline
\end{tabular}

Analyses were performed using modal approach, solving the bridge dynamics equations of equilibrium in generalized coordinates through a state space transformation based on the first twenty modes. The vibration modes of Cuntan Yangtze bridge were shown in Fig. 15. 


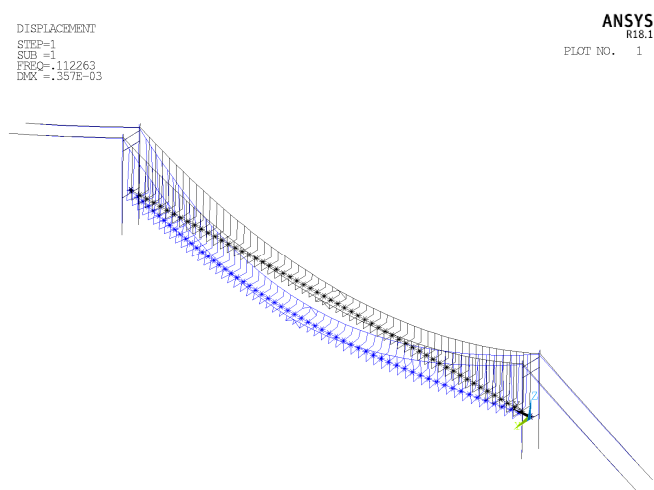

a) First vibration mode

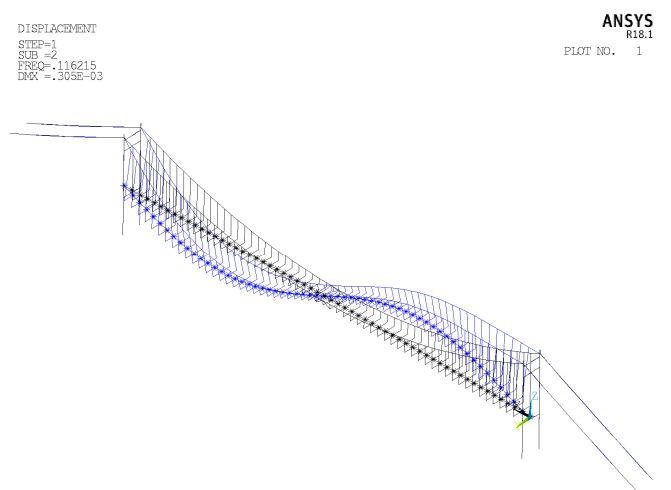

b) Second vibration mode

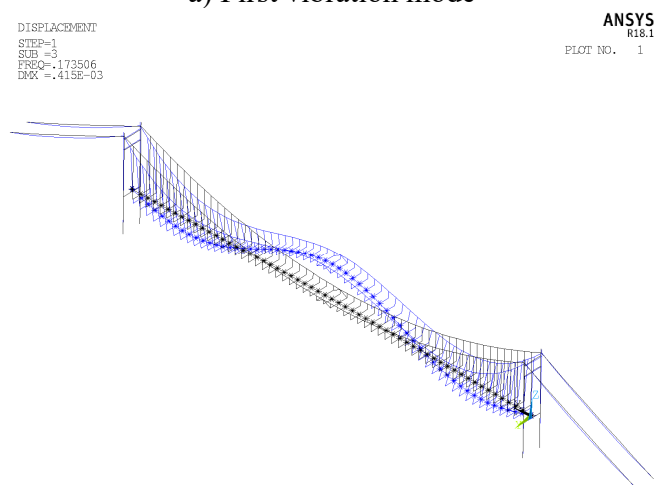

c) Third vibration mode

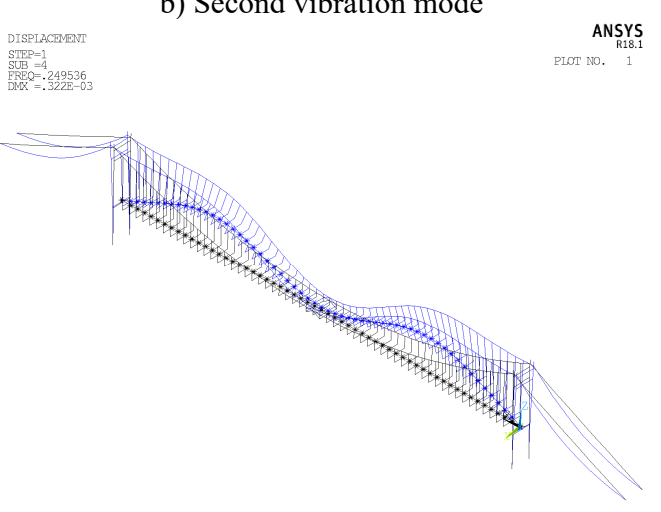

d) Fourth vibration mode

Fig. 15. Vibration modes of Cuntan Yangtze bridge

From Fig. 15, it can be summarized that the fundamental frequency is $0.1122 \mathrm{~Hz}$, corresponding to the symmetric lateral bending vibration of girder, and the basic period of structure is short. The second frequency is $0.1162 \mathrm{~Hz}$, corresponding to antisymmetric vertical bending vibration. This vibration mode of second frequency conforms to basic rule of the dynamic performance of the flexible structure. In the first twenty order vibration mode, vibrations of main cable and girder are taken as the principal vibration modes, without vibrations of main tower appearing. It is probably due to that stiffness of main tower is considerably larger than stiffness of main cable and girder. The distribution range of first twenty modal frequency is $0.1122 \mathrm{~Hz}$ to $0.4702 \mathrm{~Hz}$, and distribution of overall frequency is relatively wide.

\section{Analysis of buffeting performance}

\subsection{Vibration of main girder}

The buffeting performance of long-span bridge was calculated at $0^{\circ}$ wind attack angle, $28.1 \mathrm{~m} / \mathrm{s}$ wind speed, with consistent mass matrix and Rayleigh damping. The damping ratio was 0.005 and the time step was $0.125 \mathrm{~s}$. The computation time was $600.0 \mathrm{~s}$. The resistance lift force and pitching moment aerodynamic admittance and the aerodynamic admittance coefficient derivative were taken as 1.0, Sears function and fitting function. RMS values in vertical, transverse and torsional direction of main girder were given in Fig. 16 with different aerodynamic admittance.

From Fig. 16, the following conclusions can be summarized: (1) RMS buffeting performances of main girder in three directions were basically symmetric centering the mid-span node. From $1 / 4$ to $3 / 4$ span, buffeting performance in three directions varied moderately. For sections near the 
span-ends, buffeting performance in three directions varied steeply. (2) Both lateral displacement and torsional displacement extreme value turned up at the mid-span. Extreme value in vertical displacement turned up at the $1 / 4$ and 3/4 span. (3) In general, the buffeting performance of long-span bridge with Sears function, fitting function and 1.0 were well correlated. It was attributable to the accuracy of the bridge model. RMS buffeting performance of main girder with three different functions showed that the influence of aerodynamic admittance was remarkable. (4) The buffeting displacements from Sear function was close to that when the aerodynamic admittance function was taken as the fitting function. When the aerodynamic function taken as 1.0 , the buffeting displacements were totally larger than the other two cases. Hence, if there is no available measured aerodynamic admittance function, the function is suggested to be taken as Sear function. If conservative design is indeed needed, the function is suggested to be taken as 1.0 for the safety.

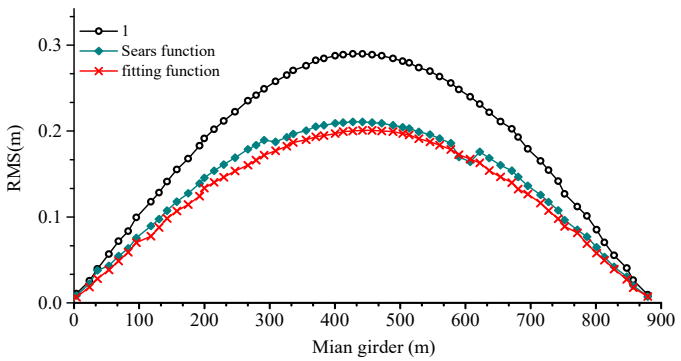

a) Lateral displacement

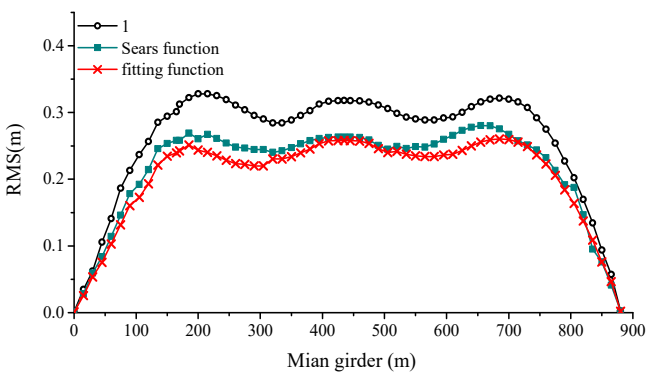

b) Vertical displacement

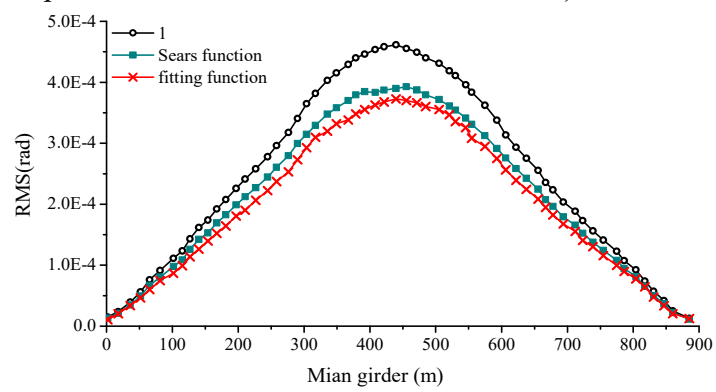

c) Torsional displacement

Fig. 16. RMS buffeting performance of main girder

\subsection{Vibration at different wind speeds}

In order to search the relationship of wind speed and aerodynamic admittance influence, buffeting performance of long-span bridge at different wind speeds were collected. The wind speed changed from $20.0 \mathrm{~m} / \mathrm{s}$ to $60.0 \mathrm{~m} / \mathrm{s}$, with an interval of $5.0 \mathrm{~m} / \mathrm{s}$. Sears function, 1.0 and fitting function were used to calculate the buffeting performance with the same turbulent wind. Comparison of RMS, internal force and bending moment were given in Figs. 17-19.

From Figs. 17-19, the following conclusions can be summarized: (1) In the calculation range of wind speed, buffeting performance of long-span bridge kept the same trend, in all three directions. The vibration in vertical direction was largest, the vibration in lateral direction was second, and the vibration in torsional direction was smallest. (2) When the aerodynamic admittance was taken as 1.0, buffeting performance of long-span bridge was most obvious. When the aerodynamic admittance was taken as the fitting function, buffeting performance was relatively unapparent. (3) With the increasing of wind speed, aerodynamic admittance influence on buffeting performance become obviously. When the aerodynamic admittance was taken as 1.0, the buffeting performance was overestimated. Buffeting performance in vertical direction was 
most overestimated. (4) The deviation of three kinds of aerodynamic admittance was smallest in lateral direction, and the deviation was largest in vertical direction. This phenomenon was more evident in reduced natural frequency. (5) The fitting function was closer to the buffeting performance of bridge. The buffeting performance can be overestimate when the aerodynamic admittance was taken as 1.0.

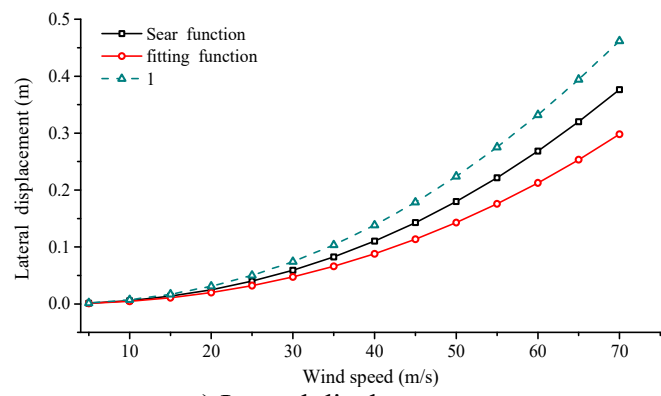

a) Lateral displacement

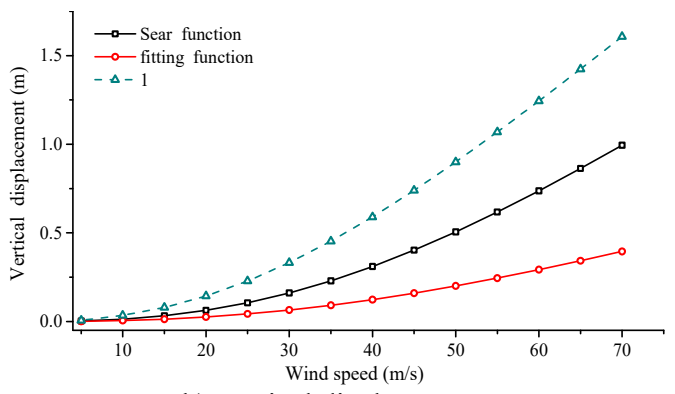

b) Vertical displacement

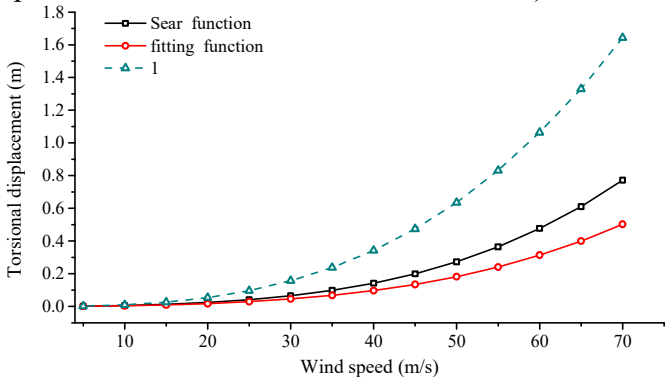

c) Torsional displacement

Fig. 17. Comparison of RMS with the different aerodynamic admittance

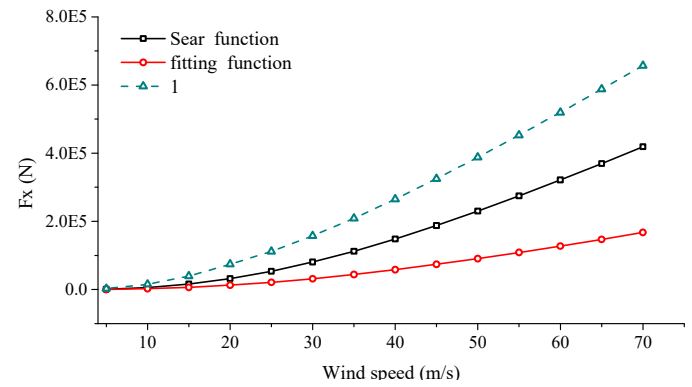

a) $F_{x}$ mean square

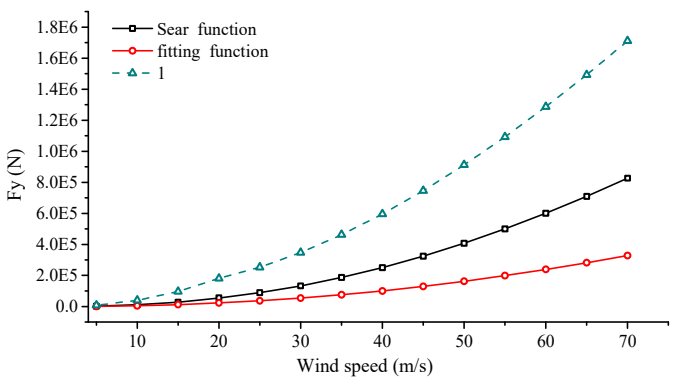

b) $F_{y}$ mean square

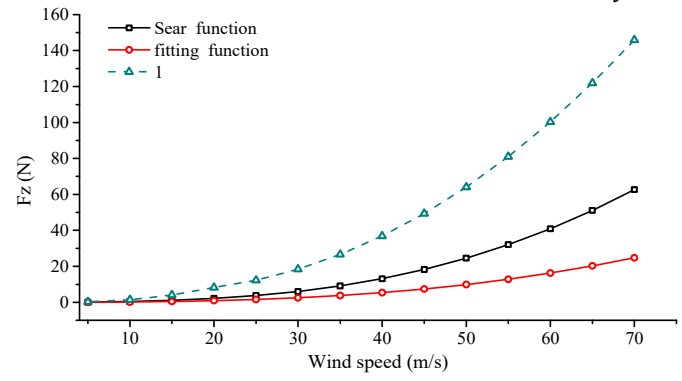

c) $F_{z}$ mean square

Fig. 18. Comparison of internal force with different aerodynamic admittance 
AERODYNAMIC ADMITTANCE INFLUENCE ON BUFFETING PERFORMANCE OF SUSPENSION BRIDGE WITH STREAMLINED DECK.

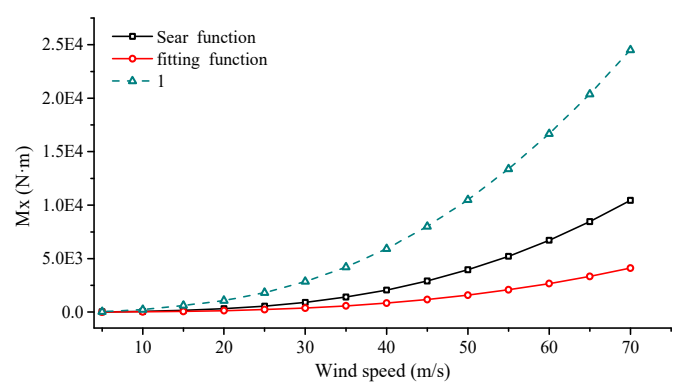

a) $M_{x}$ mean square

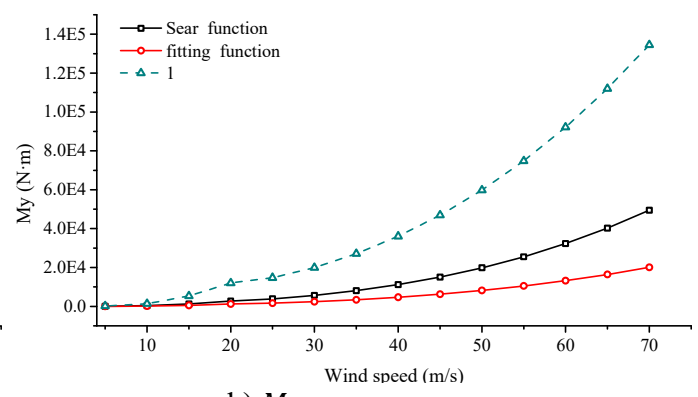

b) $M_{y}$ mean square

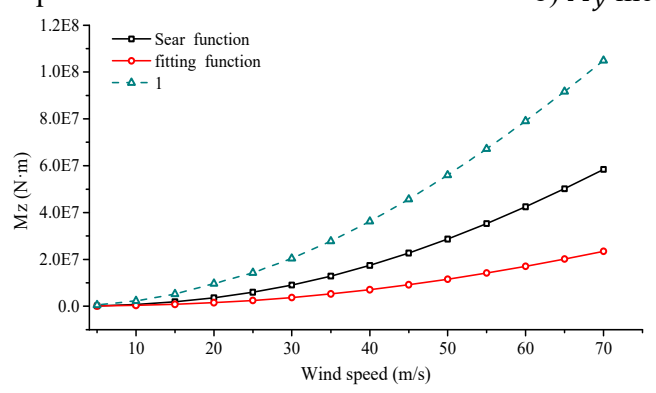

c) $M_{z}$ mean square

Fig. 19. Comparison of internal force with different aerodynamic admittance

Yao Gang contributed to the conception of the study. Yang Yang contributed significantly to analysis and manuscript preparation and wrote the manuscript. $\mathrm{Wu}$ Bo performed the data analyses. Liu Lianjie helped perform the wind tunnel test. Zhang Liangliang helped perform the analysis with constructive discussions.

\section{Conclusions}

These conclusions are particularly relevant to long-span suspension bridges with relatively streamlined deck cross-sections on buffeting performance in the natural wind.

1) The aerodynamic admittance function identification result for a bridge deck is closely related to wind attack angle. Nevertheless, there is no distinct relationship between admittance function and wind attack angle under the conditions of wind tunnel test in this paper. The aerodynamic admittance function identification results have a small difference in the different wind speed working conditions.

2) Lift admittance was the largest in the aerodynamic admittance. Draft admittance increased obviously with the increasing of wind attack angle, and the trend of change was evident. Lift and moment admittance decreased with the increasing of wind attack angle, and the trend of change was slighter than draft admittance. More investigation utilizing the actively simulated flow characteristics are expected.

3) The influence of aerodynamic admittance on buffeting performance of bridge is affected by the wind speed significantly. The influence increases rapidly with the increasing of wind speed. And this appearance is most obvious in vertical displacement, otherwise in lateral displacement.

4) Under given conditions, adopting the Sears function as the admittance function of a similar streamlined box girder is reasonable, while the buffeting performance result obtained by adopting an admittance function as 1.0 is very conservative.

\section{Acknowledgements}

This study is financially supported by the National Natural Science Foundation of China (51578098 and 51608074), Fundamental Research Funds for the Central Universities 
(106112017CDJXY200009, 106112016CDJRC000101), Graduate Scientific Research and Innovation Foundation of Chongqing (CYB17042).

\section{References}

[1] Etienne C., Jasna B. J., Jónas S. Buffeting response of a suspension bridge in complex terrain. Engineering Structures, Vol. 128, 2016, p. 474-487.

[2] Hu L., Xu Y. L. Extreme value of typhoon-induced non-stationary buffeting response of long-span bridges. Probabilistic Engineering Mechanics, Vol. 36, 2014, p. 19-27.

[3] Fenerci A., Øiseth $\mathbf{O}$. Measured buffeting response of a long-span suspension bridge compared with numerical predictions based on design wind spectra. Journal of Structural Engineering, Vol. 143, 2017, p. 4017131.

[4] Mao J. X., Wang H., Tao T. Y., et al. Effects of the turbulent spatial correlation coefficient on buffeting responses of a triple-tower suspension bridge. Journal of Vibration and Shock, Vol. 35, Issue 10, 2016, p. 202-206.

[5] Huang M. H., Lin Y. Y., Weng M. X. Flutter and buffeting analysis of bridges subjected to skew wind. Journal of Applied Science and Engineering, Vol. 15, Issue 4, 2012, p. 401-413.

[6] Guo Z. W., Ge Y. J., Zhao L., et al. Linear regression analysis of buffeting response under skew wind. Wind and Structures, Vol. 16, Issue 3, 2013, p. 279-300.

[7] Wang H., Asce A. M., Li A. Q., et al. Comparison of ambient vibration response of the Runyang suspension bridge under skew winds with time-domain numerical predictions. Journal of Bridge Engineering, Vol. 16, 2011, p. 513-526.

[8] Wang H., Hu R. M., Xie J., et al. Comparative study on buffeting performance of Sutong bridge based on design and measured spectrum. Journal of Bridge Engineering, Vol. 18, Issue 7, 2013, p. $587-600$.

[9] Hu L., Xu Y. L., Huang W. F. Typhoon-induced non-stationary buffeting response of long-span bridges in complex terrain. Engineering Structures, Vol. 57, 2013, p. 406-415.

[10] Zhang Z. T., Xie X. H. Wind-induced stochastic buffeting responses of bridges based on a varying frequency-increment sweeping method. Engineering Mechanics, Vol. 31, Issue 8, 2014, p. 101-107.

[11] Debasis K., Samit R. C., Masanobu S. Conditional simulation of non-Gaussian wind velocity profiles: Application to buffeting response of Vincent Thomas suspension bridge. Probabilistic Engineering Mechanics, Vol. 29, 2012, p. 167-175.

[12] Wang H., Tao T. Y., Cheng H. Y., et al. A simulation study on the optimal control of buffeting displacement for the Sutong Bridge with multiple tuned mass dampers. Journal of Zhejiang University: Science A, Vol. 15, Issue 10, 2014, p. 798-812.

[13] Wen Y. K., Lu W. L. Parametric optimization and analysis of distributed TMD for buffeting response control of cable-stayed bridges. China Civil Engineering Journal, Vol. 47, Issue 6, 2014, p. 88-96.

[14] Domaneschi M., Martinelli L., Po E. Control of wind buffeting vibrations in a suspension bridge by TMD: Hybridization and robustness issues. Computers and Structures, Vol. 155, 2015, p. 3-17.

[15] Nariman N. A. Control efficiency optimization and Sobol's sensitivity indices of MTMDs design parameters for buffeting and flutter vibrations in a cable stayed bridge. Frontiers of Structural and Civil Engineering, Vol. 11, Issue 1, 2017, p. 66-89.

[16] Phan D. H., Kobayshi H. An experimental study of flutter and buffeting control of suspension bridge by mechanically driven flaps. Wind and Structures, An International Journal, Vol. 14, Issue 2, 2011, p. $153-165$.

[17] Phan D. H., Nguyen N. T. Flutter and buffeting control of long-span suspension bridge by passive flaps: Experiment and numerical simulation. International Journal of Aeronautical and Space Sciences, Vol. 14, Issue 1, 2013, p. 46-57.

[18] Phan D. H., Kobayshi H. Analytical and experimental study on aerodynamic control of flutter and buffeting of bridge deck by using mechanically driven flaps. Structural Engineering and Mechanics, Vol. 46, Issue 4, 2013, p. 549-569.

[19] Tao T. Y., Wang H., Li A. Q. Influence of mid-tower on buffeting performance of a long-span triple-tower suspension bridge with continuous span. Journal of Vibration, Measurement and Diagnosis, Vol. 36, Issue 1, 2016, p. 131-137.

[20] Li Y. L., Wang D. X., Wu C. P. Aerostatic and buffeting response characteristics of catwalk in a longspan suspension bridge. Wind and Structures, An International Journal, Vol. 19, Issue 6, 2014, p. 665-686. 
[21] Wang H., Li A. Q., Zhao G. W., et al. Non-linear buffeting response analysis of long-span suspension bridges with central buckle. Earthquake Engineering and Engineering Vibration, Vol. 9, Issue 2, 2010, p. 259-270.

[22] Zhou Q., Zhu L. D., Zhao C. L. Numerical analysis on stochastic buffeting of cable-stayed bridge with slotted deck. China Civil Engineering Journal, Vol. 47, Issue 8, 2014, p. 98-106.

[23] Wang H., Xu Z. D., Tao T. Y., et al. Field measurement study on the EPSD of non-stationary buffeting response of Sutong bridge based on WT. Engineering Mechanics, Vol. 33, Issue 9, 2016, p. 164-170.

[24] Kim B. C., Yhim S. S. Buffeting analysis of a cable-stayed bridge using three-dimensional computational fluid dynamics. Journal of Bridge Engineering, Vol. 19, Issue 11, 2014, p. 04014044.

[25] Ibrahim K., Morgenthal G. Pseudo three-dimensional simulation of buffeting response under turbulent wind. Engineering for Progress, Nature and People, 2014, p. 309-316.

[26] Tubino F. Relationships among aerodynamic admittance functions, flutter derivatives and static coefficients for long-span bridges. Journal of Wind Engineering and Industrial Aerodynamics, Vol. 93, 2005, p. 929-950.

[27] Costa C. Aerodynamic admittance functions and buffeting forces for bridges via indicial functions. Journal of Fluids and Structures, Vol. 23, 2007, p. 413-428.

[28] Massaro M., Graham J. M. R. The effect of three-dimensionality on the aerodynamic admittance of thin sections in free stream turbulence. Journal of Fluids and Structures, Vol. 57, 2015, p. 81-90.

[29] Hejlesen M. M., Rasmussen J. T., Larsen A., et al. On estimating the aerodynamic admittance of bridge sections by a mesh-free vortex method. Journal of Wind Engineering and Industrial Aerodynamics, Vol. 146, 2015, p. 117-127.

[30] Zhao L., Ge Y. J. Cross-spectral recognition method of bridge deck aerodynamic admittance function. Earthquake Engineering and Engineering Vibration, Vol. 14, 2015, p. 595-609.

[31] Hua X. G., Ni Y. Q., Chen Z. Q., et al. An improved perturbation method for stochastic finite element model updating. International Journal for Numerical Methods in Engineering, Vol. 73, 2008, p. $1845-1864$.

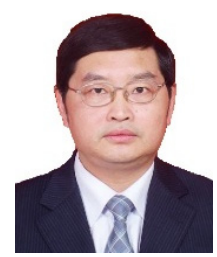

Yao Gang received Ph.D. degree in Civil Engineering Institute from Chongqing University, Chongqing, China, in 2002. Now he works at Chongqing University. His current research interests include control and dynamics of building in construction.

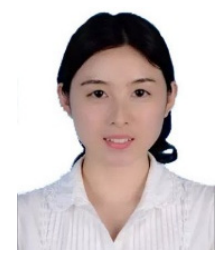

Yang Yang received Ph.D. degree in Civil Engineering Institute from Chongqing University, Chongqing, China, in 2016. Now she works at Chongqing University. Her current research interests include wind induced vibration of bridge.

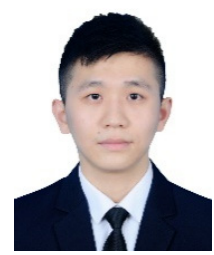

Wu Bo is a Ph.D. candidate in Civil Engineering Institute from Chongqing University, Chongqing, China. Now he is a Ph.D. candidate of Chongqing University. His current research interests include wind induced vibration of bridge. 
AERODYNAMIC ADMITTANCE INFLUENCE ON BUFFETING PERFORMANCE OF SUSPENSION BRIDGE WITH STREAMLINED DECK.

YAO GANG, YANG YANG, WU BO, LIU LIANJIE, ZHANG LIANGLIANG

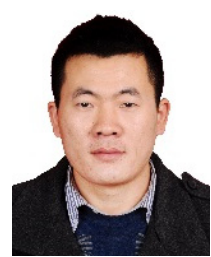

Liu Lianjie is a Ph.D. candidate in the College of civil engineering at Chongqing University. Meanwhile, he works in Chongqing Construction Science Research Institute. His current research interests include structural health inspection and reinforcement technology.

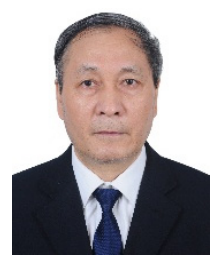

Zhang Liangliang received Ph.D. degree in Civil Engineering Institute from Southwest Jiaotong University, Chengdu, China, in 1994. Now he works at Chongqing University. His current research interests include control and dynamics of building in bridge engineering. 